\title{
Research on Artistic Characteristics of Network Animation Short Films in New Digital Media Era
}

\author{
Yu Wang \\ School of Art and Design \\ Huanghe Science and Technology College \\ Zhengzhou, China \\ e-mail: 284329183@qq.com
}

\begin{abstract}
Digital media era taking computer technology as carrier has rapidly developed since the 1980s. Changing industrial science and technology brings great convenience to people's lives and it constantly becomes focus of attention. Along with quick and widespread popularity of the internet, network technology under emerging media development becomes mainstream media communication means of digital media. As one important animation form of network media of digital media technology, network animation short films have been more frequently acknowledged. Meanwhile, diversity, interactivity, convenience design of Flash network animation becomes a new form of audio-visual media animation and an important research object currently.
\end{abstract}

Keywords—new digital media; network animation short films; artistic characteristics

\section{New Digital Media ERA Ushered in NeW DEVELOPMENT OF ANIMATION ART}

Intervention of digital information technology in animation art transmission mode changes the way of animation art creation and animation art appreciation and further influences and changes the thought process of animation art and finally the birth of animation art in new media era is hastened. Therefore, research on animation art carrier and spreading has special significance for the whole research for new media animation art.

\section{A. New Digital Media Technology Era}

Constant technology progress today provides strong and forceful technical support for rich development of art form; along with science and technology innovation, " digital new media art" becomes one typical new art development in the new media era. In this era with continuous surprises, constant innovation of art allows us see the powerful development vitality of digital media. For example, the key cultural tourism project "Iron Pagoda light and shadow show---Legend of Iron Pagoda" forged by Henan Kaifeng Municipal Party Committee and Municipal Government in March 2014 becomes key culture industry project in Henan Province, new landmark and new business card of Kaifeng tourism. "In order to present enchanting and beautiful visual feast, Iron Pagoda light and shadow show adopts 4D imaging technique in technology, also includes a series of science and technology means such as holographic technique, water curtain movie, laser modeling and building projection. In order to strengthen vacant and holy sensory feelings of Buddhism inspiration, increase the smell sensory of the audience by spraying fragrance mist, and take smart and pure Buddhism themed music as background, make the audience enjoy comprehensive visual, auditory and smell feelings when they watch the light and shadow show and truly immersive in feeling the Buddha dharma and tasting weal and woe "Fig. 1". ${ }^{[1]}$

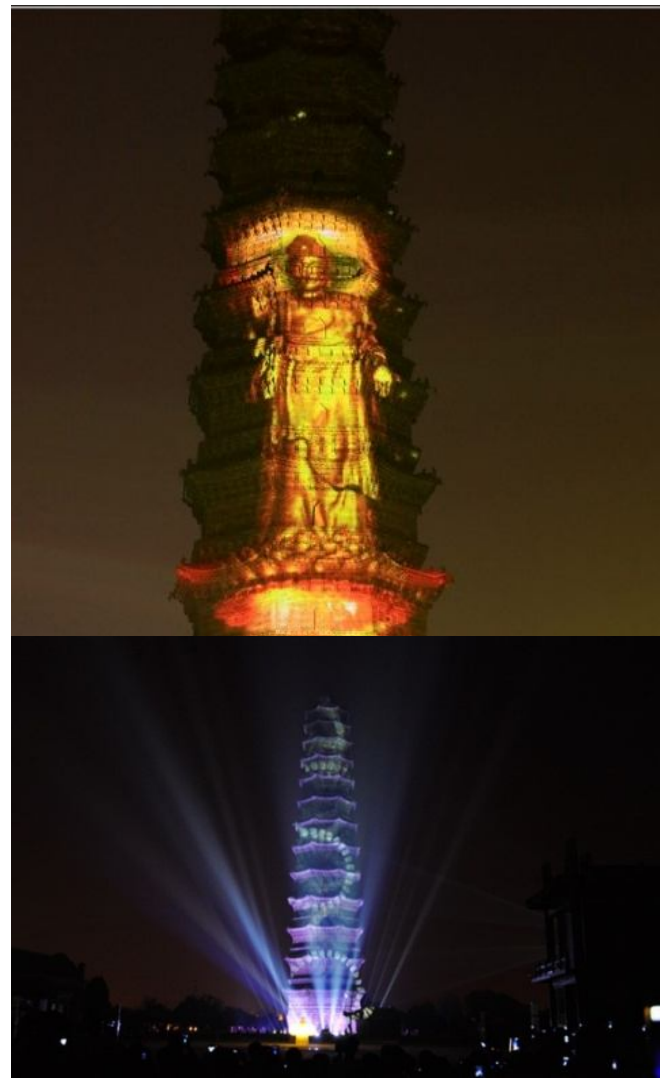

Fig. 1. Iron Pagoda Show in Kaifeng, Henan Province 


\section{B. New Development of Animation Art}

Invention of film technology dated from the end of 19th century, artists and scientists at that time started trying to create animation art. The support of new media, animation art develops animated film, animation telefilm and network animation and other different expression forms in succession. These animation art types with different forms begin their flourish development stages respectively in succession. Animation follows rapid progress of information technology, potential of animation industry development and industrialization prospect, charm and cultural significance of animation art has gradually become people's focus.

"The earliest animation art is created by people with both hands, later along with development mode of animation art; the animation is kept on the paper. Developed animation is active on the curtain and animation art shows on the movie screen, while animation art form in new media era can be seen everywhere on computer and network. Indeed, animation art goes through a series of verified art form. It evolves from cavern painting, hand shadow play, art of shadow play. From this development, human's efforts to capture image of animated objects are very forceful. People vividly record motor process expression by virtue of their powerful wisdom strength. " $\left[{ }^{2]}\right.$ Traditional animation has many limitations whether from production or broadcast on television. Along with popularity of network media, the trouble that many people don't want to spend too much time and money in the cinema and before television is improved. People turn to loving watching network animation with main characteristics of broadcast convenience. Therefore, network animation is developed quickly and effectively.

\section{CHARACTERISTIC OF NETWORK ANIMATION}

\section{A. Simple Operation---Flash Software}

As one very popular two-dimensional vector animation production software, due to simple operation, Flash has become one of the most common software in current network animation design. Because space usage of document made by Flash software is very small, the document is spread more convenient in limit network resources. Flash is one art form with likability characteristics integrated with imaging, animation and interactivity, and also one unique expression form of network animation. Therefore, from this aspect, it can be seen that Flash drives development of network animation.

\section{B. Technical Characteristics-Interactivity}

Interactivity is unique characteristics of network animation. "Interactive animation is gradually developed by combination of computer multimedia technology, interactive technique and network technique. As the product of combination of computer science and technology and art form, interactive animation realizes visual reality natural technology through computer, which makes the audience's visual time full of infinite rich forms." [3] As substantive characteristics of digital media art in new period, interactivity of network animation has played an important role in the current field of digital media art.
Compared with traditional art communication platform, characteristics of network interactive animation can make the audience get rid of the only viewer identity, which does not only increase the interest of the audience, but also proves effective of transferring information better. Application of network interactive animation changes single expression form of traditional animation art. Nowadays, interactive network animation possessed by network new media platform technology is applied to people's all living fields more and more widely, plus support of interactive technology, people really feel convenience and efficiency in life. For example, network media, mobile phone media, game, virtual reality, interface tart and other fields,

"considering that expression of interactive animation art form is different from other traditional animation art without interactive function generally, during play, contents development of animation art can be influenced by expectation and operation of the audience, therefore, in the aspect of time sequence of animation short films play, inherent linear or circular play sequence can be influenced and changed. Open change of the new type of interactive animation art in play time promotes the audience to make active discovery and feeling for animation contents as well as acquire rich message." ${ }^{[4]}$

\section{Characteristics of Culture and Art}

As emerging animation art form, network animation is not merely favored by the wide audience; network animation short films also play an important role in culture and art spreading. They show rich characteristics in deeper art and culture expression level when showing animation art.

1) Edutainment: Same with all other animation art, network animation short films have strong entertainment function, entertainment function is also main function of Flash network animation and entertainment of network animation runs through the whole creation all the time. In the Flash network animation works, most plots are humorous and funny or with sharp satire or thought-provoking. Exaggerated role modeling design bring relaxed and happy visual feeling to the audience in more random and extreme deformation expression. Network animation artists blend pleasant graphics and text information into network animation works through rich creation and spread it to wider crowd. However, we must see the artistic value of network animation and cannot only pay attention to its enjoyment. For example, CCTV public service network animation advertising film Watch the World Cup in a Civilized Way (as shown in Fig.3) adopts typical Flash network animation expression form which educates people not to disturb others' rest when watching World Cup at night. The short film adopts animation expression technique of two-dimensional vector graphic, telling people one thing with pedagogical meaning friendly and making people accept instruction in relaxing rhyme. 


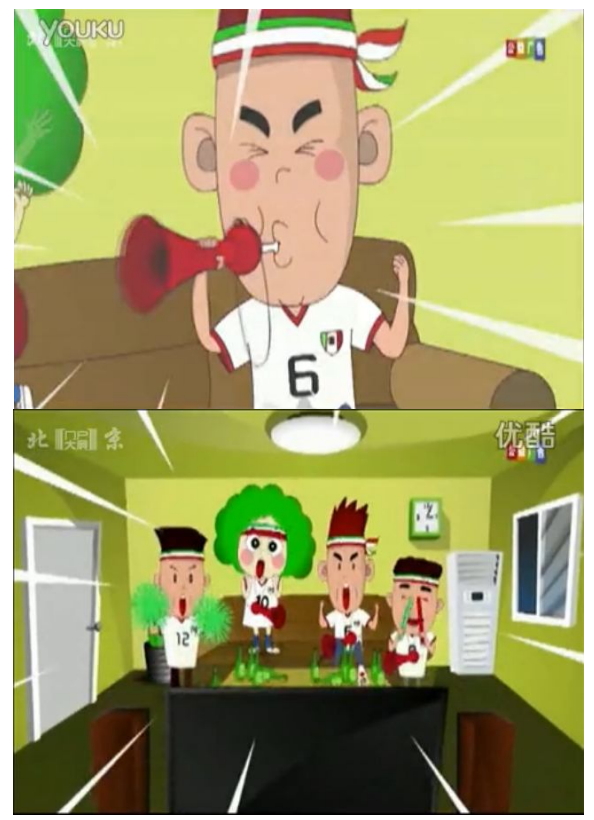

Fig. 2. CCTV Public Service Network Animation Advertising Film "Watch the World Cup in a Civilized Way"

2) Artistic pursuit. With the help of new media transmission, network animation short films are gradually breaking the limits of "high culture" and "pop culture" , "adult culture and children culture" in conventional sense. Network animation short films art is given obvious commercial characters in today's creative industry, which also aspects the degree of this new art form expanding and pursuing consumption audience. However, because creation of network animation needs flexible originality and fastpaced manufacturing, pure artistic pursuit in traditional definition is faded to some degree. For example, for materials selection of network animation short films, the creators will pay more attention to the current focus and fashion topics; for the whole representation style of short films, network animation tends to pursue life, emotion and humor and other representation elements; fro expression technique of network animation, pursue bold and exaggerated modeling, make the short films have strong taste as well as create humorous and reasonless subtitles and dubbing, etc. Network animation short films have typical new media propagation characteristic: virtuality, interactivity, matching up communication platform of new digital media, fast propagation speed, wide range and large audience, influence of all these elements also forms unique "fast-food culture" attribute of network animation short films. For example, the popular network animation serial "Miss Puff" (as shown in Fig. 4) on Youku video network, this serial takes the young's city fashionable life as theme expression, adopts "interactivity" production mode of each synchronous link. Fashion and emotion become the young audience's focusing point, plus new audio-visual language, they are popular with wide audiences. Miss Puff in "Miss Puff" is called "the most fashionable cartoon figure" by net friends.

With the help of communication of the new media of, network animation short films adopt multiple popularizing processes to pursue higher art breakthrough and reach higher level artistic aesthetics value of digital virtual world. However, in order to make network animation short films develop healthily on one "bright road" , joint efforts of authors, audience and network monitoring and so on are needed more.

\section{New DEVElopment OF NeTwORK ANimation IN New Digital Media ERA}

Under the influence of new media era, animation art has gone through development from traditional animation to new type animation, how to accurately define this emerging art animated film? Famous French film historian and film critic Georges Sadoul (1904 - 1967) once described animated film "animated film is still one art mainly based on stop-motion shooting, but not only adopting this method. From the perspective of aesthetics, animated film mainly follows expression form of traditional animation and still uses image and modeling to show, meanwhile there is a trend to exclude reproducing roles and their motions with shooting skills and mechanical method, animated film tends to model art more and does not completely belong to film in the conventional sense." [5] Under the influence of new media, whether animation creators should consider "to interpret life state through traditional hand drawing 'continuous pictures', which can keep natural color and characteristics more visually. Whether such animated film can reflect origin and value of animated film art more realistic from drawing and symbolism." $"[6]$.
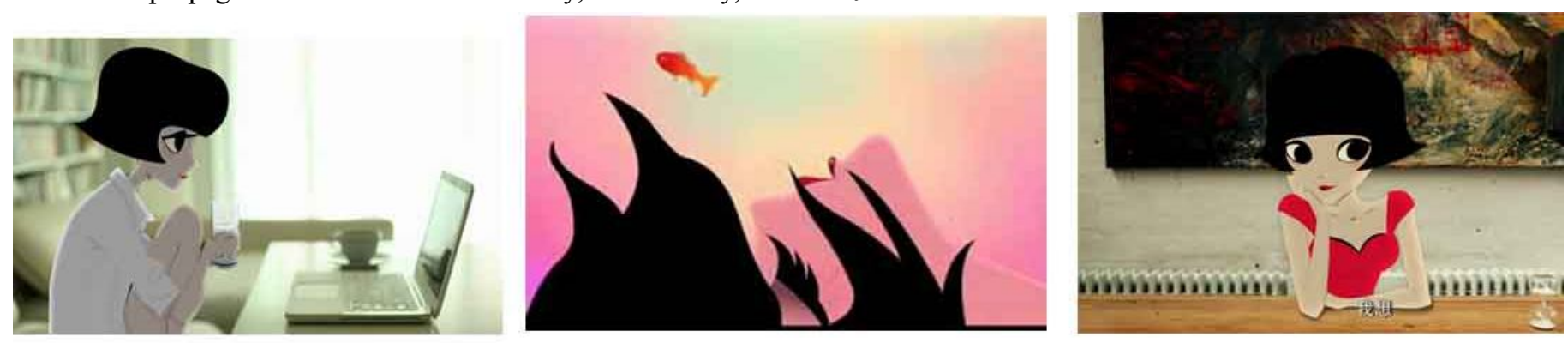

Fig. 3. Network Animation Short Film---"Miss Puff" 


\section{A. Network Animation in the Context of Three-Dimensional Special Effects Films Gathering}

The current cinemas have been basically occupied by 3D special effects animated film, but high status of threedimensional animated film on cinema market cannot show clearly the end of traditional animated film life on the market. In recent years, along with innovation and development of internet technology, original network animation short films show increasing momentum, which cannot be ignored. Humor and relaxed rhyme of network animation short films also capture the hearts of most audience; especially various humorous, funny animation short films with unique characteristics are favored by the audience more and more. These network short films mainly rely on spread method on the internet, but ultrahigh click rate fully expresses the audience's love for them. "Domestic network animation short film "Lee's Adventures" was popular on the internet in 2009 and 'called the most amazing domestic animation in 2009', such high evaluation fully demonstrates the audience's strong love for the network animation short film. Stories of the animation short film and involved fashionable elements all come from fashionable life of the current people. Just good public praise and the public support can make commercial value of network animation all show, the creator sees the business opportunity of only twenty minutes network animation short film becoming popular on the network. Then two years later, the best cameraman Peter Pau who has won Academy Award acts as artistic consultant and the creator of short film Li Yang acts as director, the popular actors act as though starring in a live-action film. Lee's Adventures is shot." "[]] In this new digital media era, commercial value of network animation has received significantly more attention. From these successful network animation transformation cases, we can see that the era of reflecting network animation short films value has come, coming of this era does not only brings objective commercial value, but also provides wider creativity performance platform for creators and makes the audience enjoy richer animation works with diversified artistic value.

Because of the promotion of digital media platform, creation and production of network animation short films do not have constraint of environment capacity in the conventional sense. Bold innovation and protean creating style of network animation brings refreshing audio-visual feelings to the audience and makes up the defect of single media platform of cinema and television lacking interactivity. Along with development of Tudou video, Suhu video, Qiyi and other video websites, the original network animation short films and animated films ushered in a big stride new opportunity. As one media almost without threshold, the network provides a convenient display platform for the creators as well provides opportunity for expression forms diversity of network animation short films.

\section{B. Influence of Internet Audience Demand on Network Animation Network Development}

"According to "Statistical Report on Internet Development in China" in 2011, video netizens in our country has reached 325 million people. Data in the report shows that age distribution of netizens mainly focuses on 2039 years old, accounting for more than 55 . $6 \%$ of total netizens. This huge number shows that network group is good at acquiring domestic and foreign animation information at full speed and can share resources on the internet expertly., ${ }^{[8]}$ Entertainment demand and fast acquirement demand for information of the audience becomes the audience demand undertaken by network animation in new media era. Because modern life pace is compact and people will face various pressures. Network seems to be the best method to release the heart. Internet integrates the world's information resources and fast acquirement for information is people's widespread habit.

\section{Talents Training for Network Animation}

Although a series of phenomena show that artistic value and commercial value of network animation has large, strong momentum, from development phenomenon of our current animation art, animation industry pays more attention to production of "animation movie", training for creative talents of network animation cannot be ignored.

“According to relevant data, currently, about $28 \%$ of institutions of higher learning in our country have established relevant majors of animation subject, college students of animation major in institutions of higher learning have exceeded 400 thousand, which can be called the animation major education system with largest scale and most students in the world." ${ }^{[9]}$ From animation education development history and development scale in recent years, we can see that animation professional education in Chinese universities has appeared since the early 1950s. Nowadays animation major throughout the country cultivates more than one hundred thousand graduates every year. Nearly five hundred thousand students are studying in the universities. Although this is a huge number, animation industry market in our country is still in the state of lacking talents. This contradiction makes us pay deep attention to the problem in animation major higher education in our country. Graduates lack work experience, while animation companies need innovation skilled animator, to solve this problem, we should adopt more reasonable talents training mode most suitable for animation major development.

"University-enterprise cooperation" is one cooperation road with better effects explored by animation talent training in colleges and universities in recent years. During cooperation, schools can cultivate professional talents geared to the needs of actual animation "competitive market" , enterprises can select proper talents to train them more specially according to development direction of company and specific project demand and further reserve talents for future development of the company. As one win-win cooperation pattern, university-enterprise cooperation is adopted by many colleges and universities.

\section{CONCLUSION}

Development and improvement of new media technology, increases the potential value of network animation art.. 
Along with progress of science and technology, vigorous vitality of network animation short films has greater force enhancement. However, in this new digital media era, development of various art needs more space, the same with network animation art, more fresh blood needs to be injected to acquire broader development space. During development of network animation art, corresponding change must be made according to new era characteristics, in this way, more advances and promotion can be acquired. This so-called change does not only reflect maturity of artistic characteristics of network animation, but also shows richer form during combination of new digital media. Along with science and technology advancement and times development of new digital media technology, network animation enriches artistic expression forms of animation with more diversified communications media and wider application scope and it has become one of the most popular animation forms currently. Diversity, interactivity and convenience of network animation short films becomes the audience's selection and love powerful support. Rich aesthetic satisfaction of broad audience has been paid more attention to. Artistic value and commercial value of network animation will be expressed more remarkably. New media provides wide display platform for network animation contents and its development will be a trend which cannot be ignored.

\section{REFERENCES}

[1] Yang Jing. Iron Pagoda Light and Shadow Show [electronic document]. http://www.kf.cn/special/140425/, 2014

[2] Dai Chuanshun. Animation Culture and Its Progress[D]. Master's Thesis of Shandong Normal University. 2007: 4-5

[3] Cheng Xiaojun, Zhai Haopeng. Interactivity Animation Research on FLASH Network Animation Technology under New Digital Technology in New Era [J]. Dazhong Wenyi, 2013(3) : 158

[4] Cheng Xiaojun, Zhai Haopeng. Interactivity Animation Research on FLASH Network Animation Technology under New Digital Technology in New Era [J]. Dazhong Wenyi, 2013(3) : 158

[5] Georges Sadoul. History of Film[M]. Translated by $\mathrm{Xu} Z \mathrm{Zhao}, \mathrm{Hu}$ Chengwei. 1995 (2)

[6] Li Sida, Chen Yang. Network Animation Value under the Background of 3D Movies[J]. Journal of Beijing University of Posts and Telecommunications: Social Science Edition 2012(5) : 14

[7] Wang Yu. Research on Artistic characteristics of Experimental Animation Film in the New Media Context [D]. Master's Thesis of Northwest University. 2012: 27

[8] Xu Ying. Audience Demand of Network Media and influence on Network Animation Creation [J]. Hunan Packaging, 2012(3):37-39

[9] Xiao Yongliang. Status Analysis of Animation Education in China [J]. Journal of Beijing Union University (Humanities and Social Science), 2011, 9(3) : 73-77 